\title{
A Review on Fire Protective Functional Finishing of Natural Fibre Based Textiles: Present Perspective
}

\author{
Ayan Pal ${ }^{1 *}$, Ashis Kumar Samanta ${ }^{1}$, A Bagchi ${ }^{1}$, Pubalina Samanta ${ }^{2}$ and Tapas Ranjan Kar ${ }^{3}$ \\ ${ }^{1}$ Department of Jute and Fibre Technology, University of Calcutta, India \\ ${ }^{2}$ Department of Fashion \& Apparel Design, Rani Birla Girls College, India \\ ${ }^{3}$ Department of Khadi and Textiles, Mahatma Gandhi Institute for Rural Industrialization (MGIRI), India
}

Submission: July 9, 2020; Published: September 29, 2020

*Corresponding author: Ayan Pal, Department of Jute and Fibre Technology, Institute of Jute Technology, University of Calcutta, India

\begin{abstract}
Cotton, jute and other natural fibre based textile fabrics are gaining popularity in domestic and international field due to its eco-friendliness and biodegradability characteristics and carbon sequestering advantages. This natural fibres based textile fabrics, if can be finished with natural or eco-friendly synthetic fire-retardant chemicals to satisfy the Required standard, it gets an extra dimension in the market and has a huge demand, if it is cost competitive. Cotton, jute, wool and silk based natural fibres have wide differences in their composition and properties and some inherent properties in common are higher flammability, higher moisture absorption and susceptibility to rotting/microbial attack, poor crease recovery etc., which have restricted its growth of their uses towards protective technical/functional textiles, though they have certain genuine advantages too as agrorenewability, bio degradability etc. To find more uses of such natural fibres as high valued technical textiles, as value added technical textiles, these natural fibre based textile fabrics have to undergo certain property modifications by specific improved chemical finishing as required especially for fire retardancy, water repellency, rot resistance etc. depending on its end use applications [1,2]. For the development of various types of functional finishing of jute and other natural fibres that too with eco-friendly formulations and processes, proper choice of eco safe chemicals along with suitable eco safe process parameters and optimization of process variables, water and energy requirement/consumption etc., are must and important for sustainability. So, in this review paper, different aspects of Fire-Retardant finishing of Jute and other natural fibre based textiles and their present perspectives have been discussed.
\end{abstract}

Keywords: After glow time; Cotton; Char length; Fire retardant finishing; Functional finishing; Jute; LOI values; Pad-Dr-cure process; Natural fibres; Silk; Wool

\section{Introduction}

Now-a-days, fire-retardant textiles are being produced in large quantities due to prevailing legislations for fire safety and public awareness. Demand for fire-retardancy of jute and other natural fibres based materials, is also increasing in market for EcoFriendly concern. Some important uses as fire protective technical textiles materials besides children apparels are furnishing and cover decorative fabrics as curtain or table cover, jute brattice cloth in mines, pandal fabrics in temporary structure, homeupholstery, automotive fabrics, floor coverings, tents, kitchen apron and gloves etc. , which should preferably be fire retardant.

Before proceeding further for understanding ways and means of Fire Protective action by different types of Fire Retardant Chemicals, the burning cycle of different fibres/polymers and their thermal degradation behaviour for different types of textiles/ polymers must be understood well, to make any attempt to reduce or to prevent fire propagation/flame spreading on burning of any textiles and preferably the flame be extinguished. Burning of fibres/ polymers by combustion is a complex process involving a multitude of steps, when left unchecked, combustion becomes selfcatalyzing cycle and will continue until the oxygen, the fuel supply or the excess heat is depleted and is best described in qualitative terms. Figure 1 is a schematic diagram of the various steps which combine to establish the polymer combustion process. The three essential stages require to initiate the combustion are heating, thermal decomposition or pyrolysis and ignition. Ignition occurs either spontaneously (auto ignition) or due to the presence of an external source such as a spark of a flame/burning flame.

To understand the above burning cycle/mechanisms of each fibres is essential for subsequently finding/determining/selecting 
suitable flame retardant agent that will be most suitable to act spontaneously on that polymer/fibres to prevent /stop or to

reduce flaming action/flame spreading action, exact knowledge of the followings are required

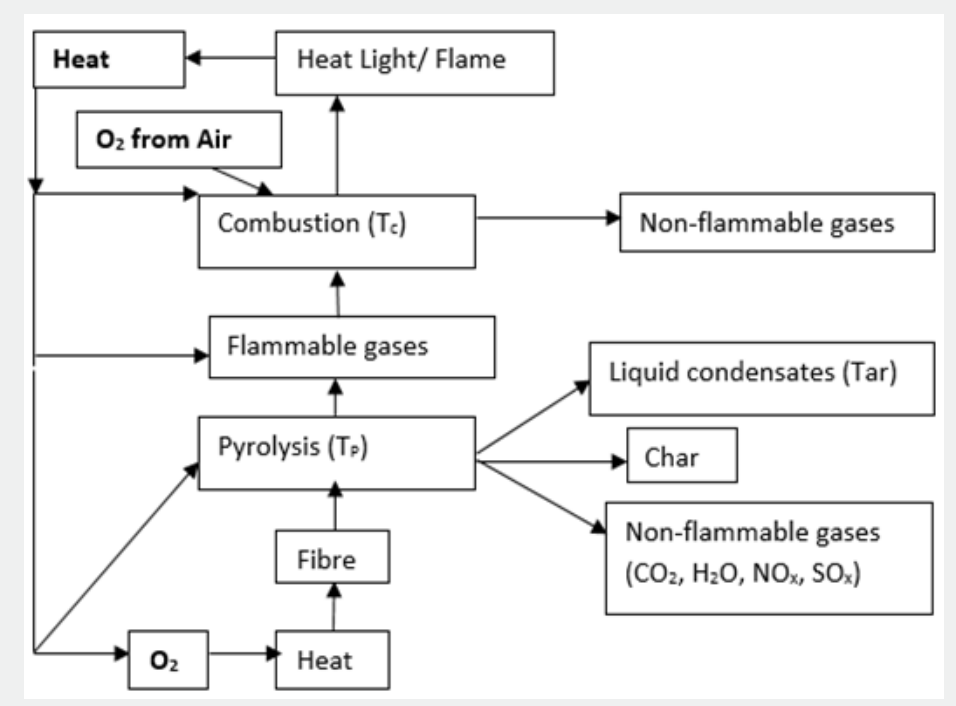

Figure 1: Schematic Diagram of the Combustion Cycle for Fibres.

i. Thermal transitions and degradative/pyrolytic behaviours of each fibre material concern.

ii. Enhancement of pyrolytic temperature/combustion temperature, if possible, by chemical interaction.

iii. Chemical Interactions of flame-retardant agents with the fibres for enhancing char formation.

iv. Chemistry of the flame-retardant agents/formulation and their mode of function

v. Method of application and conditions of treatment for application of flame-retardant agents. vi. Use of suitable Catalyst and supportive agents for required enhanced action at right time.

vii. To make Fire Retardant action to be wash fast by ensuring fixation of Fire-Retardant agents.

Natural and synthetic textile fibres, are when exposed to a source of sufficient heat/flame, will start burning and gradually (depending on their thermal transitions temperatures) will decompose or 'pyrolyse' evolving flammable volatiles to promote fire/flame, which need to be combat and to reduce or stop rapidly. (Table -1) provides a list of known thermal transition temperatures of different textile fibres:

Table 1: Thermal Transitions of Common Textile Fibres.

\begin{tabular}{|c|c|c|c|c|c|}
\hline Fibres & $\mathrm{T}_{\mathrm{g}}\left({ }^{\circ} \mathrm{C}\right)$ & $\mathrm{T}_{\mathrm{m}}\left({ }^{\circ} \mathrm{C}\right)$ & $\mathrm{T}_{\mathrm{p}}\left({ }^{\circ} \mathrm{C}\right)$ & $\mathrm{T}_{\mathrm{c}}\left({ }^{\circ} \mathrm{C}\right)$ & LOI* \\
\hline Wool & - & - & 245 & 600 & $23-25$ \\
\hline Cotton & - & - & 350 & 350 & $15-18$ \\
\hline Viscose & - & - & 350 & 420 & $17-19$ \\
\hline Nylon-6 & $47-50^{\circ} \mathrm{C}$ & 215 & 431 & 460 & $20-21$ \\
\hline Nylon-66 & $50^{\circ} \mathrm{C}$ & 265 & 403 & 530 & $20-21$ \\
\hline Polyester & $78-80$ or $80-90$ & 255 & $420-447$ & 480 & $20-22$ \\
\hline Acrylic & 100 & $>320$ & $290^{+}$ & $>250$ & 18.2 \\
\hline Polypropylene & -20 & 165 & 469 & 550 & 18.6 \\
\hline Nomex & 275 & 375 & 410 & $>500$ & $28-30$ \\
\hline Kevlar & 340 & 560 & $>590$ & $>550$ & $29-30$ \\
\hline Jute & -- & -- & $\begin{array}{l}\text { Hemi-Cellu- } 290^{\circ} \mathrm{C} \\
\text { Cellulose- } 360-370^{\circ} \mathrm{C}^{+} \\
\text {Lignin }-425-450^{\circ} \mathrm{C}^{+}\end{array}$ & -- & $20-21$ \\
\hline
\end{tabular}

Source: *Fibres having $<21 \mathrm{LOI}$, readily burns in air, ad fibres having $\geq 27 \mathrm{LOI}$ is considered to be FR, However, to consider as complete and safe fire retardant materials, it is better to have materials of LOI nearly $35-36$ atleast. 
As individual fibre/polymer differ in composition and the structure their decomposition temperature ranges vary within certain limits. The rate of pyrolysis will be accelerating leading to an increasing supply of fuel to the flame which then spreads over the polymer surface. Major interest for flame retardancy of textile is the fact that when the textile products burn how to render them less likely to ignite and if they are ignited, to burn much less efficiently. The phenomenon is termed as "Flame Retardance". Flame retardants act to break the self-sustaining polymer combustion cycle and thus extinguish the flame or to reduce the burning rate in a number of possible ways for flame retardant action on specific textiles to stop or to reduce propagation of flame during burning of fibrous polymers. So, Flame retardancy in Textiles may be achieved by the followings ways and means either by individual or combined mode (a to f) as follows:

a) To use of such fire-retardant materials that thermally decompose through strongly endothermic reactions. So that heat required for thermal decomposition is not achieved easily. $\mathrm{T}_{\mathrm{p}}$ of the fibre should not reach and no combustion takes place easily. For this purpose, Aluminum hydroxide or Alumina trihydrate and Calcium carbonate and even chain a-clay/alumina etc. is incorporated as filler in polymers and coatings.

b) To apply of a material that forms insulating layer around the at temperature below the fibre $\mathrm{T}_{\mathrm{p}}$ of the fibres. Boric Acid and its hydrate salts $\rightarrow$ when heated the low melting compounds release water vapour and produce a foamed glassy surface on the fibre insulating the fibre from the applied heat and oxygen.

c) To influence the pyrolysis reaction to produce less flammable volatile and more residual char to achieve fire retardancy of textile. This 'condense phase' mechanism is in the action by phosphorous-containing fire retardant, which after having produced phosphoric acid through thermal decomposition, crosslink with hydroxyl-containing polymers $\rightarrow$ altering the pyrolysis pattern to yield less flammable by-products. Another explanation $\rightarrow$ is the blocking of primary hydroxyl group in the C- 6 position of the cellulose units, preventing formation of flammable by products (levo-glucosan) these phosphates catalyse the dehydration and promotes char formation and prevent the formation of levoglucosan, the precursor of flammable volatiles.

d) To prevent combustion by erecting interference with the generated free radicals $(\mathrm{Br} . / \mathrm{Cl}$.) from fire retardant agents reducing available heat. Such materials act in 'gas phase' mechanism, which includes halogen containing fire retardant compound, which during combustion, yield relatively long lived hydrogen halides, less reactive free radicals, for effectively reducing the heat available for perpetuating the combustion cycle and which decreases the oxygen content in the surrounding air by halogen/hydrogen halide gas generation.

e) To enhance $T_{c}$ (Combustion Temperature), the temperature at which flammable bye products/fibre-fuel reduces, interference with the flame retarding agent during burning. f) To modify/enhance of the initial decomposition temperature, i.e temperature of pyrolysis $\left(\mathrm{T}_{\mathrm{p}}\right)$ at which prevent/reduces significant volatile formation and increases char formation/nonflammable gaseous volatile formation.

Review on Fire Retardant Chemicals and Fire Protective Finishing Processes

Several works are available in literature on flammability and flame retardancy of textiles like cotton, rayon and other textiles for centuries. An early description of flame-retardant cellulosic materials has been found in a British patent granted to Obadiah WYLD IN 1735. This patent described the use of alum, borax and vitriol to prevent the flaming of paper, pulp or textiles [1]. In 1821, significant contributions were made to the development of a flame-resistant finish for linen and jute fabrics by Gay Lussac [2] and there the flame resistance was obtained by the use of a mixture of ammonium phosphate, ammonium chloride and borax.

The earlier ideas of flame retardancy, reviewed by Reeves et al. [3] are often defined in terms of coating, gas, thermal and catalytic dehydration theories. The coating theory may operate by (a), (b) and (c) functioning singly or in combination. The gas theory considers retardants which cause gas formation at temperatures below their ignition temperature (mode (c)) and/or the gases produced which do not burn at normal flame temperatures but merely dilute the flame (e.g. $\mathrm{CO}_{2}, \mathrm{HCl}, \mathrm{H}_{2} \mathrm{O}, \mathrm{SO}_{2}$ operate by mode (b) the thermal theory describes retardants which function in terms of (c) and often these agents undergo endothermic changes such as fusion, sublimation or loss of water of crystallization. Obviously release of non-flammable volatiles here will involve pathway (b). Catalytic degradation describes flame retardants which promote char and water vapour formation and so involve functions (b) and (c).

Rarely do flame retardants operate by a single mode and it is more common to refer now days to their retardant activity functioning in the condensed phase (modes (a), (f), (c)), in the vapour (or gas) phase (modes (b) and (e)) or both. For instance, the traditional borax and boric acids/borates mixtures and similar acid generating salt systems function in the condense phase by promoting char formation and, in some cases, impart a glassy impervious coatings in front of the advancing flame $[4,5]$ their action has been fully reviewed by Pitts [6] More recently Nakanishi [7] has demonstrated that of a variety of commonly available flame-retardants for cellulose, the boric acid-borax system is the safest with regard to carbon monoxide and smoke production during burning.

A general review of the action of non-durable, semi-durable and durable flame retardants has been carried out by Reeves et al. [3] and Kasem \& Rouette [8]. The most important group of flame retardants are those containing phosphorus and in most fibre/ polymer subtrates, function in the condensed phase as char promoters. Weil [9] and Aenishaenslin [10,11] have comprehensively discussed available types of such agents and their 
mechanisms of action. Phosphorous-based retardants function only if the fibre structure is capable of undergoing transformation to char and in the case of thermoplastic fibres like polyamide and polyester, melt and drip which may thus prevent such action.

In many flame retardants the presence of nitrogen has an additive and, in many cases, a synergistic effect on the performance of phosphorus containing retardants. Consequently, many commercially available flame-retardant contain both phosphorous and nitrogen. This interaction has critically reviewed by Weil [12], Khanna \& Pearce [13] and by Einsele [14] who specially refers to their activity also in synthetic fibres. Those organophosphorus flame retardants containing synergistically active nitrogen and which are particularly suitable for use on cellulosic textiles, function in more than one way. Current opinion $[13,15]$ suggests that the nitrogen acts as a nucleophile with respect to the phosphorous entity thereby creating polymeric species having polar P-N bonds. The enhanced electrophilicity of the phosphorous increases its ability to phosphorylate the C-6 primary hydroxyl group on each anhydro glucopyranose repeat unit within the cellulose molecule. This prevents the intramolecular $\mathrm{C}(6)-\mathrm{C}(1)$ laevoglucosan-forming reaction to occur which is the main volatile flammable gas produced as fuel formed during pyrolysis of cellulose. Simultaneously, the Lewis acidicity of the electrophilic phosphorous promotes dehydration and char formation. The mechanism of Fire-Retardant action of different fire-retardant agents acting on Cellulose are described in the review made by Horrocks and Book edited by Horrocks on fire retardancy subject $[15,16]$.

Thermal degradation of cellulosic material proceeds through a complex series of concurrent and consecutive chemical reactions [16] which are schematically illustrated in Figure 2 Individual reactions are influenced by the temperature and rate of heating, by the environment (particularly oxygen, water and other reactive or inert gases) and by the composition and physical form (surface area) of the substrate. Formation of levoglucosan, an important volatile flammable gaseous intermediate generates by thermal degradation of cellulose, which takes place at higher temperatures. According to another report [17] followings are the general stages of action of heat on ligno-cellulosic natural polymers \& woody substance (though it may vary from fibre to fibre depending on the composition and inter unit linkages):

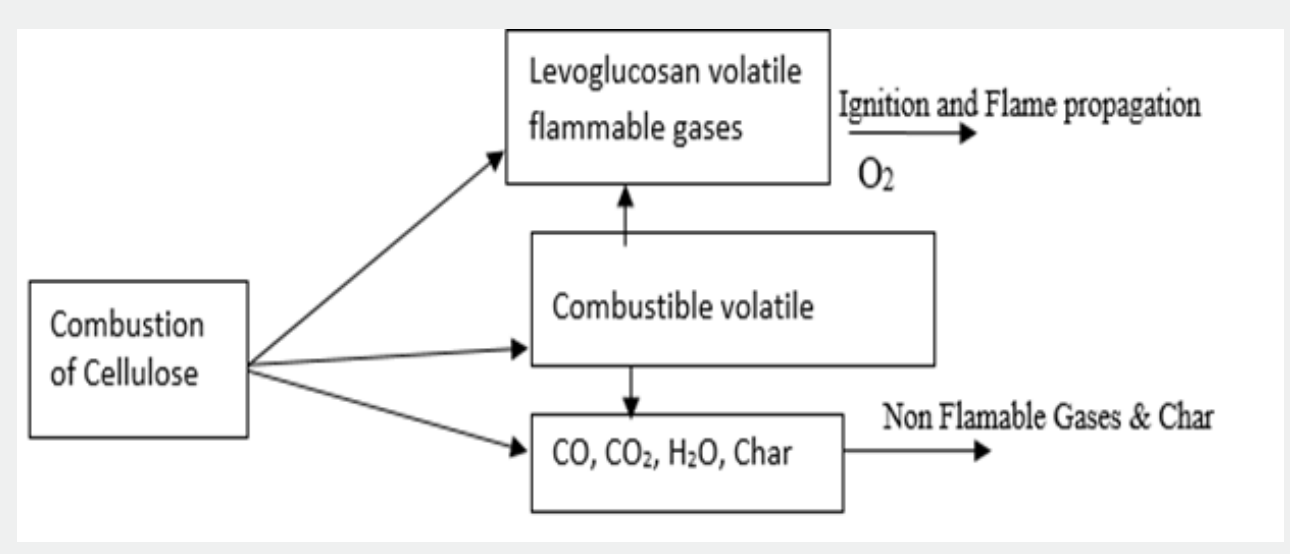

Figure 2: Thermal Degradation of Cellulose.

From 55 to $1050 \mathrm{C}$ approx. \pm 5oC $\rightarrow$ Removal of absorbed moisture

150-200oC $\rightarrow$ Slow start of thermal decomposition of the low molecular weight compounds of natural polymers/fibres like jute.

$>\mathbf{1 8 0 0 C} \rightarrow$ Hydrolysis of low molecular weight polysaccharides (hemicellulose) begins [Hemicellulose release more incombustible gasses \& fewer tarry substance. According to Saunders and Allcorn gasses released most frequently contain about $70 \%$ of incombustible $\mathrm{CO}_{2}$ and about $30 \%$ of combustible CO].

200-260oC $\rightarrow$ Exothermic reaction begins. [Characterized by increase emission of gaseous products of decomposition, release of tarry substance and appearance of local ignition areas of hydrocarbons with low boiling points].
260-300oC $\rightarrow$ Initial decomposition of cellulose starts. [Primarily responsible for the formation of flammable volatile compounds. Uncontrolled release of considerable quantities of heat begins and increased amount of liquid and gaseous products (including methanol, ethanoic acid) formed.

300-400oC $\rightarrow$ Active process of decomposition for cellulose occur and completed. [Ignition of thermal decomposition products, flame spread by combustible gases and increase in heat release and mass loss rates].

400-500oC $\rightarrow$ Thermal Decomposition of lignin Starts and completed.

Above 500oC $\rightarrow$ Formation of combustible compounds is almost nil or very small, however the residual Char formation increases. 
In another report, It is mentioned [18] that moisture is evaporated from jute in between $30-110^{\circ} \mathrm{C}$, hemicellulose show exothermic hump at around $260-300^{\circ} \mathrm{C}$ (with DSC peak at $293^{\circ} \mathrm{C}$ ), though $10 \%$ weight loss is obtained in jute at $>100^{\circ} \mathrm{C}$, after which decomposition rate accelerates; while the cellulose decomposes at around $300-380^{\circ} \mathrm{C}$ (Showing endothermic peak/Hump at 360 $365^{\circ} \mathrm{C}$ ) and lignin decomposition nearly occur at $400-450^{\circ} \mathrm{C}$ (Showing exothermic peak/small hump at $420-430^{\circ} \mathrm{C}$ ).

\section{Fire retardancy finishing of jute}

Jute brattice cloth used in coal mines. Tent-fabric and upholstery fabric for fire -safety needs to be finished with a fire-retardant finish. It is reported that the treatment with $6.75 \%$ potassium sodium tartarate (PST) on jute results in a complete self-extinguishing property. This is not durable, but it can withstand steaming and brushing. Also, Potassium sodium tartarate (Rochelle salt) was applied on jute for fire retardancy [19]. However, this treatment cannot render jute LOI above 30 to show acceptable flame-retardant property. There are several flame retardant chemicals to improve LOI values for cellulosics and also applicable for lignocellulosic textiles like Jute using Borax, Di-Ammonium Phosphate, Borax: Boric Acid (7:3) mixture, Ammonium sulphamate: Ammonium phosphate (85:15), phosphoric acid etc. which are either non-durable or semi durable type, even if applied in conjunction with some binder or cationic resin finish or using amino silicone binder emulsion. The nondurable flame retardant is mechanically entrapped, or some way adhered /anchored onto the fabric surface and thus, becomes somewhat semi durable if it can be insolubilized on the fabric surface by suitable after treatment or by suitable binder treatment. The jute fabric is padded with $5 \%$ polyacrylate emulsion (PrimolHA) along with flame retardant chemicals, a combination of Borax, Boric acid, Di-Ammonium hydrogen Phosphate=7:3:5 ratio in proportion of $1: 1$ then dried at $100^{\circ} \mathrm{C}$ for 10 minutes and cured at $130^{\circ} \mathrm{C}$ for 3 minutes it shows reasonable fire retardant property [20].

Among several popular durable synergestic flame retardant agents available for synthetics and cellulosics, the very useful and important combinations are

i. Antimony-Halogen compounds or Antimony oxychloride/ Antimony oxide with Chlorine or Bromine salt compounds, more suitable for Synthetic textiles and

ii. THPC i.e, Tetrakis hydroxy-methyl phosphonium chloride (THPC), Tris-1-aziridinyl phosphine oxide (APO), APO-THPC combination APO-Zn (BFn) $)_{2}$ or THPC-Thiourea or APO-Thiourea combinations, THPC-antimony oxide combination etc., more suitable for Cellulosics and lignocellulosic textiles used widely earlier even in industry. . But none of these are ecofriendly in today's context and hence are not used much for environmental caution and health caution purpose.

So, in jute most of the non-durable and cheaply available flame-retardant agents may be applied along with the polymeric or resin finish formulation to obtain durability to some extent. Also, the use of phosphate with melamine-formaldehyde resin has been found to be another alternative method for fire proofing jute goods as studied in BJRI, Dhaka [21].

The flame-retardant agents available and their modes of application have been partly reviewed by Lyons [4] and also chronologically by Tesoro [22]. More comprehensive studies are also made available by Drakes \& Reeves [23], Lewin \& Sello [24] and very recently by Barker \& Drews [25]. Have surveyed uses/application of different fireretardants of specific nature to their use in the Indian textile industry. Effect of cellulose, hemicellulose and lignin contents on pyrolysis and combustion of natural fibers has been described by Dorez et al. [26]. Very little literature relates to other natural fibres other than cotton, except review report by Yusuf [27] including linen, hemp; silk \& wool and by Mehta \& Hoque [28] concerning flame retardation of jute.

Different fire-retardant chemicals act in different way by manipulating pyrolysis, prevention of flammable gases, less or more char formation, controlling combustion, protecting/ preventing generation of flammable gases or from heat/oxygen and fuel to combat burning/propagation of flame. The mode of action of such fire-retardant chemicals may therefore be summarized as:

i. Nitrogen-synergised phosphorylation of cellulose to block laevoglucosan formation.

ii. Lewis acid-catalysed dehydration plus some chain degradation to short chain oligomers not conducive to laevoglucosan formation.

iii. Cellulose cross-linking following phosphorylation which promotes both char formation and its consolidation.

iv. The $2^{\text {nd }}$ most important group of flame retardant are those which contain halogen atoms, notably chlorine and bromine. These operate in the vapours phase by release of hydrogen halide gas and free radicals which suppress the flame reactions. The efficiency of such retardants is enhanced by the presence of either phosphorus or antimony (antimony (III) oxide). Both antimony-halogen and phosphorus-halogen has been reported to be synergistic. Khanna [27] reviewed the evidence for synergism and suggest that antimonyhalogen activity arises from formation of the oxyhalide, SbOX, where $\mathrm{X}$ is the halogen. and mentioned optimum activity to occur for various substances at a molar ratio of $\mathrm{Sb}: \mathrm{X}=1: 3$ suggesting formation of $\mathrm{SbX}_{3}$ as an essential stage in the retardation chemistry. It would seem that initial formation of SbOX, $\mathrm{X}$ is followed by conversion to $\mathrm{SbX}_{3}$ which control release of halogen, which on decomposition scavenges flame propagating radicals such as $\mathrm{H}$ and $\mathrm{OH}$. The char-promoting tendency or phosphorylation or both of these systems of fire 
retardancy action have been observed in certain polymer systems including cellulose and lignocelluloses for different types of fire-retardant agents discussed here.

It has been found that phosphorous based compounds are effective flame retardant [29-31] for cellulosic materials. The most effective theory which has been generally accepted is that phosphorous compounds are acid precursors and these acids participate in char formation by dehydration. It has been suggested by many investigators that the addition of nitrogenous compound results in improved flame retardancy. The same level of flame retardancy can also be obtained with reduced quantities of phosphorous in the P-N system. This behaviour which is termed as "Synergestic Behaviour" of phosphorous and nitrogen has been found in the case of various flame retardants comprising phosphorous-nitrogen system [32].

Phosphoric acid and the ammonium salt of phosphoric acid are very effective in inhibiting fire propagation for cellulose $[33,34]$. Lewin et al. [24] reported that the two decades following the 1950 period were the golden age of the synthesis and development of phosphorus containing flame retardants and in particular, those for cellulose. Since mid-1970's, very few new developments have taken place and most currently available and successful commercial durable retardants were discovered during the former period.

Samanta \& Bagchi et al [35] has also described successful semidurable fire-retardant finish of jute fabrics using phosphorous and nitrogenous compounds and studied their thermal degradation behavior up to $500^{\circ} \mathrm{C}$. Phosphoric acid $[24,36]$ and its derivatives in the presence of nitrogenous buffer will esterify cellulose under elevated temperature curing conditions with minimum acceptable degradation. Reid et al. [37] also mentioned phosphorylation of cellulose forming cellulose phosphoric esters having the typical formula

$$
\begin{gathered}
\mathrm{O}^{-} \mathrm{NH}_{4}^{+} \\
\mathrm{I} \\
\text { Cell- } \mathrm{CH}_{2}-\mathrm{O} \cdot \mathrm{P}-\mathrm{O}^{-} \mathrm{NH}_{4}^{+}
\end{gathered}
$$

Also, the stannate-phosphate process is reported to give durable flame-retardant finish. The cotton fabric is padded with Sodium Stannate and ammonium sulphate followed by drying and then the fabric is further padded with diammonium hydrogen phosphate and urea [38] followed by curing. A combination of Urea-phosphate-formaldehyde resin treatment imparts an excellent durable flame-retardant property in cotton fabric [39].

Isaac et al. [40] observed that if undertaken simultaneously with sulphation, ion exchange problems are rendered tolerable.
In this system sulphation by ammonium sulphamate, $\mathrm{NH}_{2} \mathrm{SO}_{3}-\mathrm{H}$, is enhanced if phosphorylation is carried out with phosphoric triamides; diammonium phosphate may not be used because it cannot suppress the afterglow associated with the cellulose sulphate groups and the phosphorylation itself is impeded by the sulphamate. Afterglow in sulphated cellulose is associated with sodium ion exchange from soft water laundering liquors and in this system minimal afterglow and acceptable durability is achieved if Sulphur is present at about the $2 \%$ level and P/S mass ratio of 1.3-2.0 on cellulose is maintained. O'Brien investigated the durable flame resistance and other physical properties of cotton and rayon treated with cynamide and phosphoric acid [41]. The dyed cotton fabrics were treated finish with urea with phosphoric acid [42] for a durable flame-retardant method. The role of urea was that of a solvent which helps to reduce acidity and swells cellulose to enhance penetration.

\section{Durable Organo-Phosphorous Fire Retardants: Tetrakis (Hydroxymethyl) Phosphonium Derivatives}

One of the important FR agents which provide durable flame retardancy is Tetrakis (Hydroxymethyl) Phosphonium chloride (THPC) which is initially described in 1921 by Hoffman [43] and recognised as having commercial potential by Reeves \& Gutherie [44]. It is prepared as a crystalline solid from phosphine, formaldehyde and hydrochloric acid at room temperature [45].

$\mathrm{PH}_{3}+4 \mathrm{CH}_{2} \mathrm{O}+\mathrm{HCl} \rightarrow\left(\mathrm{HOCH}_{2}\right)_{4} \mathrm{P}^{+} \mathrm{Cl}^{-}$

THPC is highly reducing in character and its methylol groups condense with amines to form insoluble polymers. Consequently, it is applied to cellulose substrate in presence of amine ended species followed by curing to promote condensation and crosslinking. THPC forms the basis, therefore, of not only a variety of systems in which it is directly present, but also the principal derivatives Tetrakis (Hydroxymethyl) Phosphonium Hydroxide (THPOH) and the respective Sulphate THPS. FR finishes based on THPC-Amide, THPC-APO, THPC-Cyanamide and THPC- $\mathrm{Sb}_{2} \mathrm{O}_{3}$ have been used mostly for durable application of cotton fabric.

\section{However, Fire Retardant finish with such THPC or other phosphorous compounds with or without nitrogenous compounds causes}
i. Loss in tensile strength.
ii. Release of formaldehyde.
iii. Acid tendering of fabric during curing.
iv. Fabric handle become stiff.

Complete neutralization of THPC with Sodium Hydroxide yields a compound generally referred to as THPOH [46]. THPOHammonia has received a great deal of commercial attention due to strength retention and the fabric does not stiffen. This flame retardant is applied by padding fabric with a solution of THPOH 
and various auxiliaries, then partially drying the fabric, and finally exposing the partially dried fabric to ammonia gas [47]. THPOHammonia-Copper Complex: Copper salts were found to stabilize THPOH- $\mathrm{NH}_{4} \mathrm{OH}$ solution by forming a complex, thereby making it possible to apply ТНPOH [48] to cellulose substrate from a single bath without the use of gaseous ammonia.

Proban process: The replacement of heat curing by ammonia gas curing removed the problem of fabric tendering because of the ambient temperature is required and high accompanying $\mathrm{pH}$; the application of THPC and urea followed by an ammonia cure has been admirable developed as the Proban process patented and licensed by Albright and Wilson Ltd [49].

Phosphonic acid derivatives: Phosphonates are playing important role in the durable flame -retardant treatment of cellulose. Phosphonic acids have two reactive group which can be esterified or converted to amide. Aenishaenslin et al. [26] showed that $\mathrm{N}$ methylol derivatives of dimethyl and diethyl phosphonopropionamide and the corresponding 1-methyl propionamide are the most suitable flame-retardants for cotton. It is preferable to apply N-methylol dialkyl phosphonopropionamide (marketed by Ciba under the name Pyrovatex CP) in conjunction with aminoplast resin in order to increase nitrogen content of the treated fabric and the effectiveness of flame retardant. Pyrovatex $\mathrm{CP}$ are effective on all cellulosic fibres [50].

Aziridines: Anther durable fire retardant for cotton is Tris (1-aziridinyl) phosphine oxide (AP0) [51]. APO is highly reactive compound and can be used with cellulose by acid catalysed heat curing technique. However, the uses of THPC and APO are restricted now a days due to their toxicity problem.

Common commodity cellulosic and lignocellulosic fabrics can be made fire-resistant by treatment with different non-durable and durable fire-retardant formulations, which are readily available in literature as cited above. However most common chemical used for obtaining wash fast Flame Retardancy on cotton, Viscose, Jute, Wool, Silk etc., is a common THPC based compound (Tetra-Kis-Hydroxy methyl phosphonium chloride) commercially sold in different names by different companies (say Proban-210, Pyrovtex-CP, Sara flam-CWF, etc) and is used with an acidic catalyst by Pad-Dry $\left(100^{\circ} \mathrm{C}\right.$ for $\left.10-15 \mathrm{~min}\right)$-Cure $\left(130^{\circ} \mathrm{C}-150^{\circ} \mathrm{C}\right.$ for $3-5 \mathrm{mins}$ depending on Fabric weight/aearial density) technique followed by washing-drying and calendaring. But the THPC type of Compounds are becoming now obsolete, as it contains Methyl-Hydroxy groups i.e Methylol group and has therefore Formaldehyde release problem afterwards and hence been not eco-friendly. Here is the need started again for new research for finding low cost Fire-Retardant Chemicals which is eco-friendly as well as can impart wash fast fire retardancy to such natural fibre based textiles.

There are several non-durable flame retardant chemicals for low cost jute products such as -Borax, Di-Ammonium Phosphate, Borax: Boric acid (7:3) mixture, Ammonium sulphamate:
Ammonium phosphate $(85: 15)$, phosphoric acid etc. which if applied in conjunction with a reactive resin, the non-durable flame retardant is embedded in the binder/resin film on the fabric surface and thus, renders it somewhat semi-durable fire retardant finishing effect to jute. The jute fabric is when padded with $5 \%$ polyacrylate emulsion (Primol-HA) along with a combination of Borax, Boric acid, Di-Ammonium hydrogen Phosphate $=7: 3: 5$ ratio in proportion of $1: 1$ then dried at $100^{\circ} \mathrm{C}$ for 10 minutes and cured at $130^{\circ} \mathrm{C}$ for $3-4$ minutes it shows reasonable degree fire retardant property [20].

But after understanding need of eco-friendly fire-retardant finishing of jute and cotton as a natural fibre, further researchers are concentrated on non-THPC and Non-APO or Non-Halogen based fire-retardant finishing of jute and cotton fabrics. Recently, for establishing toxicity free fire-retardant finishes on natural fibre based textiles, formaldehyde free fire-retardant finishing has been encouraged for environmental concern [52]. Some fundamental study on the thermal behavior [53-54] of scoured/ bleached and fire retardant treated jute substrate by analysis DSC and TGA thermograms have been reported to understand the chemical interaction of specific treatment on thermal degradation temperatures of different constituents of jute substrate. Phosphorous-Nitrogen based i.e Diammonium phosphate and Urea combination of fire retarding treatment as common fire retardant finishing [55] of jute has been described in literature including as a semi durable fire retarding finish using different ratio of phosphorous and nitrogen compounds on bleached jute fabrics. Horrocks [56] has made a comprehensive review of different fire-retardant materials and their mode of action and effects on textile fabrics. Role of char formation in Fire-Retardant finishing of textiles has also been elaborated by Horrock [57]. Extensive research has been now concentrated to develop newer eco-friendly fire-retardant formulations in all different ways and means possible, some examples are as follows:

Eco-friendly Fire-retardant finishing of Jute Fabric by Impregnation or coating Phosphorylated PVA and its effect on physical properties and thermal behaviour of treated jute fabric has been reported by Samanta \& Bhattacharyay (Roy) et al. [58]. Fire retardant finishing of Jute based fabrics using Ammonium Sulphamate or sulphamic acids and Urea Combination and its process standardization for application on jute has been preliminarily reported by Samanta and Bhattacharyay(Roy) et al. [59] in recent past as a need of the hour considering the environmental protective action concern. Optimization of this fire retardant formulation with ammonium sulfamate and urea combination using statistical experiment of design software has been further reported by applying User Defined Quadratic Model (UDQM) tools for deriving response surface methodology equations to predict LOI value, Char length and Loss of Fabric tenacity for specific concentration of Ammonium Sulfamate and Urea with prefixed dosages of $\mathrm{MgCl}_{2}$ catalyst in recent report by Samanta and Bhattacharyay (Roy) et al. [60]. 
Use of nano technology applications by preparing and applying nano $\mathrm{ZnO}$ powder for obtaining fire protective finish of jute fabrics with $0.01 \%$ Nano-ZnO Powder admixed with 4-6\% poly-hydroxy amino siliconate binder have been described also by Samanta, Bhattacharyaya (Roy) \& Josh et al. [61] to establish toxicity free nano technology based fire-retardant formulations for jute fabrics. Optimization of this fire retardant formulation with Nano-ZnO Powder and poly-hydroxy amino siliconate binder combination using statistical experiment of design software has been further reported by applying User Defined Quadratic Model (UDQM) tools for deriving response surface methodology equations to predict LOI value, Char length and Loss of Fabric tenacity for specific concentration of Nano-ZnO Powder and Polyhydroxy amino siliconate binder with $\mathrm{MgCl}_{2}$ used as catalyst by Samanta, Bhattacharyay(Roy) and Bagchi et al. [62].

The mode of functions of specific flame-retardant finishes and its wash durability specifically for cellulose, wool and manmade fibres and their blends are described in depth by Horrocks [63]. Multipurpose finishes for both cellulose and wool textiles in which flame retardancy is one property along with other finishing effects conferred on the said textiles are examined in this literature where finally the effects of applying these specific flame-retardant finishes on textile related properties of the said textiles and their fire retardant performances are also reported. Khalifah Gaan \& Malucelli [64] have described a detailed review on recent advances for flame retardancy of textiles based on phosphorus chemistry and their mechanism as well as their thermal degradation behavior in 2015 .

Sustainable flame retarding finishing of cotton and Jute utilizing agro waste like banana pseudo stem (BPS) containing phosphorous, nitrogen, chlorine, silicate, and other many metallic compounds was applied $[65,66]$ on premordanted $(5 \%$ tannic acid $+10 \%$ alum) cotton cellulosic and jute lignocellulosic textiles by the pad-dry method in an alkaline condition have been reported to render LOI value up to 30 to Cotton and LoI value up to 33 to jute making natural bio-Fire Retardant finishing of Jute and Cotton. The flame retardancy of these samples was measured in terms of LOI, burning rate, total heat production and its thermal degradation was evaluated by differential scanning calorimeter (DSC), and Thermogravimetric analysis (TGA).

Eaton et al. [67] gave a comprehensive article on various test methods aimed at different sectors of industry to produce the wide range of flame retardancy test methods and standards. Ozcan et al. [68] studied that fabrics produced from coarse yarns will burn more easily than those from fine yarn because of their loose structure. Yarn count and twist factor made an influence on ignition time at the knitted fabrics increasing yarn counts decrease the ignition times and the best ignition times are obtained for yarns with a 3.6 twist coefficient. Mehta [69] has briefly considered different aspects of fire-retardant finishing with special reference to polyester and cotton.
Benisek et al. [70] show how different fabrics and finishes behave in protective clothing, designed to resistradiative, corrective and conductive heat. Dawn et al. [71] analysed the provision and properties of cotton protective apparel designed for the US Space Shuttle. They thoroughly assess the acceptability of cotton finish with a Tetrakis (hydroxymethyl) phosphonium sulphate-ureaammonia cure system for this most stringent end use. Stephenson et al. [72] surveyed both non-durable and durable treatments for non-woven products with special reference to cellulosics and polyester. Mehta et al. [73] reviewed the toxicological hazards of flame retardants are often questioned in term of the toxicity of the basic retarding chemicals and the hazards during application and end use. They studied for commonly available cellulosic flame retardants and mentioned agent like tris (aziridinyl) phospine oxide (APO) and antimony oxide can be entirely toxic. Nuessle et al. [74] showed that phosphorylation by means of cellulosediammonium phosphate reaction in the presence of urea gave rise to a flame retarding finish.

Kaushik et al. [75] have studied that a THPC-Thiourea based formulation is applied to the polyester-viscose blended fabrics by pad-dry cure procedure followed by washing to produce. FR fabrics, which retain their retardancy offer as many as fifty through laundering and trumble drying. THPC-Thiourea finish imparts the durable flame retardancy by crosslink-OH Group of cellulose portions of polyester/viscose blended fabric due to which about $15 \%$ loss in tensile strength of treated fabrics. Comparative Studies of flammability behaviour and physical properties of controlled, treated and washed fabrics are done under the different conditions. Ramchandran et al. [42] studies through two different methods for flame retardant finish to cellulosic fabric. Among this novel methods, the results proves that the Urea with phosphoric acid method is found to be the best method for durable flame retardant finish to cellulosic fabrics than stannate and phosphate step method in terms of higher flame resistance and better tensile properties and also reduced stiffness character.

Blanchard et al. [76] studied that cut pile cotton/polyester carpeting burns over the entire area upon ignition if the pile density of the carpet is sufficiently low. Chemical modification by esterification of cellulosic fibres results in restricted combustion properties. This allows such substrates to pass the standard flammability test for carpets and rugs. Cotton containing carpeting spray treated with only $5-10 \%$ polycarboxylic acid and suitable catalyst exhibits satisfactory flame suppression properties. Appropriate polycarboxylic acids are 1,2,3,4-butane tetra carboxylic acid (BTCA), Citric Acid and maleic acid with catalyst such as Sodium hypophosphite, sodium phosphate, or the partially neutralized salt of the acid. Chemical reaction and processing conditions required to achieve improved flame resistance on cotton-containing cut pile carpeting are presented. Domobrowski [77] discussed that there is a common assumption about the dangers of decabromodiphenyl Ether (DECA). It is the purpose of 
this paper to present an alternative viewpoint relative to the use of this halogenated flame retardant (FR). Brominated FRs such as DECA inhibit the chemical reaction between oxygen and fuel, preventing a fire from developing. Flame-resistant cotton fabrics have been prepared by Frick et al. [78] for treatment of the fabric with an aqueous emulsion of an organic polymer for fire retardant finishing, prepared from bromoform and triallyl phosphate. This finish is proved to be durable to repeated laundering and does not materially change other textile properties rendering satisfactory fire-retardant action. This treatment is said to be applied by conventional textile finishing equipment in industry.

Peixiu Tian et al. [79] evaluated the flammability of a cotton fabric finished with a flame retardant (FR) of ammonium salt of teraethyiene pentamine heptamethyl phosphonate (ATEPAHP), that has been grafted on cotton fabric via a P-O-C covalent bond. Where limiting oxygen index (LOI) of this treated cotton having 18\%-26\% weight gain in ATEPAHP achieved LOI value $37.0 \%-40.5 \%$ and this LOI value is reduced to $28.2 \%-31.8 \%$ after 50 laundering cycles (LCs) proving it still as fire retardant even after 50 cycles of wash. Bajaj et al. [80] studies that Diammonium hydrogen phosphate (DAP) and N-methylol resins were applied to cotton and polyester/cellulosic blends using one step and two step sequential pad-dry-cure process. Among the N-methylol resins studies, only urea formaldehyde treatment on phosphorylated cotton demonstrated the phenomena of N-P synergism in terms of oxygen index, while no clear trend could be established in blends.

Nakanishi et al. [81] studied the flame retardant of cotton fabric with nitrogen, phosphorous, sulfur, halogen and boron based compound individually or in combination of two component showed sufficient flame retardancy to cotton fabric and the flame retardant samples exhibit difference in thermal degradation behavior compared to untreated fabric. Kaur et al. [76] revealed that phosphorylation of cotton fabric as well as grafted cotton fabric through graft co-polymerisation with methacrylamide improved fire-retardant property. Eaton [77] mentioned the different flame retardancy test methods for textiles. Blanchard et al. [82] studied phosphorylation of cellulose with phosphonic acid derivatives and the physical properties have been discussed. Discoloration upon curing of phosphorylated cotton is reduced by incorporation of $1-4 \%$ of dicyandiamide.

Mamalis et al. [83] mentioned that the flame-retardant finishing of cotton affected different mechanical properties e.g. tensile, bending, shear, compression and surface properties. James R House et al. [84] studied the effectiveness of commercial flame retardant Proban on cotton clothing and concluded that Proban FR treatment was not damaged by wear and washing. Giraud et al. [85] studied the flame retarding behavior of cotton coated with polyurethane containing microencapsulated flameretardant agent. Synergism behaviour of $\mathrm{P}-\mathrm{Br}$ in polyester-cotton fabric treated with tetra bromo bisphenol (TBBA), TBBA- DAP was studied and maximum synergism was obtained when the concentration of TBBA was equal to DAP [86]. Garba et al. reported [87] that some degree of flame retardancy on cellulosic material is achievable with crosslinking agents such as dimethyl dihydroxy ethylene urea or even di methylol urea.

Post grafting reaction of Glicidyl-methacrylate (GMA) grafted cotton fabric with ethylene diamine followed by orthophosphoric acid were carried out by Reddy et al. [88] to produce fire retardant cotton fabric. FTIR analysis of gases evolved from cotton and flame retarded cotton fabric pyrolysed in air was carried out by Horrocks et al. [89]. Kandola et al. [90] studied the influence of treatment of flame retardant to cotton on the mechanism of cotton pyrolysis. Photochemical grafting of 4-vinyl pyridine onto cotton fabric for imparting flame retarding properties has been reported [91]. Nakanishi et al. [92,93] studied thermal degradation of cotton as well as flame retarded cotton and revealed that flame retardant cotton samples show extremely reduced amount and fewer numbers of gas products compared with untreated samples. Rearick et al. [94] have studied the flammability considerations for raised-surface apparel. Raised surface and light weight apparel are regulated under the General Weaving Apparel Standard (GWA). Currently for cotton raised surface (RS) apparel, the most common method for meeting the GWA standard is to blend cotton with synthetic fibres. But many companies would like 100\% cotton RS garment that pass the GWA flammability test.

From the above literature review, it is clear that amongst amples of fire retardant chemicals so far studied and some of them were established, currently for all newer development of fire retardant finishing approaches are concentrated to find low cost commercializable eco-friendly fire retardant finishing of cellulosics and ligno cellulosics and protein based natural fibre constituted textiles. Though many approaches stands to be useful, it need to reestablish its technoeconomic feasibility and wash stability satisfying National/International Standards on it as per particular specifications of fire resistant performance properties of selective different end uses, practically to come into effect for commercial uses and customer acceptability.

\section{Conclusion}

An acceptable Fire Retardant Textile Materials should exhibit LOI value nearly 35 and char length $2-4 \mathrm{~cm}$, afterglow time $15 \pm 5$ sec with minimum loss of fabric tenacity and loss in tear strength ( Both loss in fabric tenacity and loss in tear strength preferably be restricted within $20 \pm 5 \%$ after fire retardant treatments done). However, for different end uses, specifications of respective fireretardant textiles are different. However for cellulosic and other natural textile fibre based materials, it is necessary to standardize the recipe and methods for application of fire retardant finish separately particularly for cotton and its blends, and jute and jute/cotton union fabrics and again for silk and woolen textiles 
and their blends separately, as any single or one recipe and process conditions for any particular textiles will not match the requirement of other textiles, due to their compositional differences of each. Such value-added fire retardant natural fibre based fabrics may find new markets and better acceptability in international and national market, if such fire resistant as one of the important functional properties are imparted and proved to be eco-friendly. However, at present, there is no separate standards available for Eco-friendly fire retardant finish, so presently a fire Retardant finished textiles if need to get certified as eco-friendly finishes, it has to satisfy two different standards at a time, i.e it has to first meet/satisfy the parameters concern to fire retardant performances as per suitable National/International standards as per end uses and then for proving its eco friendliness, it has to meet and specification for parameters of Eco Mark scheme/OTN100 or GOTS parameters as well. Such Fire-retardant finished textiles again need to be achieved / produced at reasonable cost for market acceptability.

Hence, there is a need of continuous search/research for developing suitable recipe and methods with standardizing the process conditions for establishing suitable eco-friendly chemical formulations for production of such fire-retardant natural fibre based Cotton/Jute/Wool/Silk textiles and their blended fabrics that may be used as decorative furnishing in public places like school/ colleges, hotels. public community hall/auditorium, hospitals etc., or as Home textiles for use as curtains and table and sofa covers for home furnishing or for kitchen apron and gloves etc., besides transport furnishings such as Car /Rail/Aviation upholstery, and in many such other end-uses, besides fire fighter dresses (though the standard required for each end uses will differ). Thus, the need of future direction of research required in this field is identified and justified here to motivate current researchers in this field.

\section{References}

1. Samanta AK, Biswas SK, Bagchi Arindam and Bhattacharyya Reetuparna (2011) Semi-Durable Fire-Retardant Finishing of Jute Fabric and its Thermal Behaviour. J IE (I) Text Eng 91: 18-26.

2. Bajaj Puspa (2000) Heat and Flame Protection. Handbook of Technical Textile. In: Horrocks, Anand SC (eds.), $2^{\text {nd }}$ (edn.), Woodhead Publishing, UK pp. 223-263.

3. Reeves WA, Drake GL, Perkins RM (1974) Fire resistant textiles Handbook. Technomic pub pp. 1-241.

4. Lyons JW (1970) The Chemistry and Uses of Fire Retardants. In: WileyInterscience, UK pp. 1-462.

5. Little RW (1951) Fundamentals of flame retardancy. Text Res J 21(12): 901-908.

6. Pitts JJ (1973) Flame Retardance of Polymeric Materials. In: Kuryla, Papa AJ (eds.), USA pp. 1-133.

7. Nakanishi S, Ohkouchi F Masuko F, Nishimoto I (1991) Effects of nitrogen and phosphorus on pyrolytic gas formation from cellulosic fibers. Seni Gakkaishi 47(9): 492-498.

8. Kasem MA, Rouette HK (1972) Flammability and flame retardency of fabrics: a review. J Fire Flammab 3: 316.
9. Weil ED (1978) Phosphorus-Based Flame Retardants. In: Lewin M (ed.), Flame retardance of Polymeric materials, USA pp. 103-131.

10. Aenishaenslin R, Guth C, Hofmann P, Maeder A, Nachbur H (1969) A new chemical approach to durable flame-retardant cotton fabrics. Text Res J 39(4): 375-381.

11. Aenishaenslin R (1975) Advances in Fire Retardant Textiles. In: Bhatnagar VM (ed.), Progress in Fire Retardancy Series p. 1-31.

12. Weil ED (1975) Additivity, synergism, and antagonism in flame Retardancy. In: Kuryla WE, Papa AJ (eds.), Flame Retardancy of Polymeric Materials, USA pp. 185-243.

13. Khanna YP, Pearce EM (1978) Synergism and Flame Retardancy. In: Lewin M (ed.), Flame-retardant Polymeric Materials, USA p. 43-61.

14. Einsele U (1976) Melli and Textilber 57(1): 64.

15. Barker RH, Hendrix JE (1979) Flame retardance of cotton and other naturally occurring cellulosic polymers. In: Kuryla WC, Papa AJ (eds.), Flame Retardancy of Polymeric Materials USA p. 1-65.

16. Horrocks AR (1983) An Introduction to the Burning Behaviour of Cellulosic Fibres. J Soc Dyers Color 99(7-8): 191-197.

17. Horrocks AR, Price D (2001) Fire Retardant Materials. In: $1^{\text {st }}($ edn.), Woodhead Publishing Ltd, UK pp. 1-448.

18. Samanta AK, Dev D, Ghosh P (1998) Simultaneous free radical polymerization and acidic polycondensation of acrylamideformaldehyde resin on jute fabric. J Applied Polymer Science 64(13): 2473-2489.

19. Sharma US (1986) Fire Retardancy of Jute Fabric with Potassium Sodium Tartrate (Rochelle Salt). Colourage 33: 19-20.

20. Banarjee SK, Dey A, Ray PK (1986) Fireproofing jute. Text Res J 56(5): 338-339.

21. Samanta AK (1995) Chemical finishing of jute and jute blended textiles. Colourage 42(2): 1-37.

22. Tesoro GC (1978) Chemical modification of polymers with flameretardant compounds. J Polym Sci Macromolecular Reviews 13(1): 283-353.

23. Drake Jr GL, Reeves W (1971) Flame-Resistant Textiles, Cellulose and Cellulose Derivatives, High Polymers. In: Bikales NM, Segal L (eds.), Wiley-Interscience, USA pp. 1-1293.

24. Lewin M, Sello SB (1975) Flame retardance of polymeric materials. In: Lewin M (ed.), USA pp. 1-19.

25. Barker RH, Drews MJ (1985) Cellulose chemistry and its applications. In: Nevell TP, Zeronian SH (eds.) pp. 1-552.

26. Dorez G, Ferry L, Sonnier R, Taguet A, Lopez-Cuesta JM (2014) Effect of cellulose, hemicellulose and lignin contents on pyrolysis and combustion of natural fibers. J Anal Appl Pyrolysis 107: 323-331.

27. Mohd Yusuf (2018) A Review on Flame Retardant Textile Finishing: Current and Future Trends. Current Smart Materials 3(2): 99-108.

28. Mehta RD, Hoque AKMM (1982) Communication to the Editor: Flammability of Metal-Cation-Exchanged Jute Fabrics. Text Res J 52 (9): 607-608.

29. Tesoro GC, Sello SB, Willard JJ (1969) Nitrogen-Phosphorus Synergism in Flame-Retard Ant Cellulose. Text Res J 39(2): 180-190.

30. Tesoro GC (1967) Flame Retardants for Cotton Fabrics. Textilveredlung 2(7): 435-440.

31. Reeves WA (1972) Durable Phosphorus-Containing Flame Retardants for Cellulosic Textiles. Text Chem Colorist 4(2): 43-47. 
32. Kandola BK, Horrocks AR, Price D, Coleman G (1996) Flame-Retardant Treatments of Cellulose and Their Influence on the Mechanism of Cellulose Pyrolysis. Revs Macromol Sci Part C Chem Phys 36(4): 721794.

33. Davis FV, Frindlay J, Rogers E (2008) The urea-phosphoric acid method of flameproofing textiles. J Text Inst 40(12): 1-52.

34. Brit Pat (1948) To Joseph Bancroft and Sons Co. In Technology and test methods of flameproofing of cellulosics, ed by M Lewin, SB Sello Flame-retardant polymeric materials, Springer.

35. Samanta A K, Biswas S K, Bagchi A, Bhattacharyay R (2011) Semidurable fire-retardant finishing of jute fabric and its thermal behaviour. IE(I) Joumal-TX 91(1): 18-20.

36. Nada AMA, Moussa WM, Abd El Mongy S, Abd El Sayed ES (2009) Physicochemical studies of cotton Ion exchange wood pulp. Australian J of Basic and App Sci 3(1): 9-16.

37. Reid J D, Mazzeno L W (1949) Preparation and Properties of Cellulose Phosphates. Ind Eng Chem 41(12): 2828-2831.

38. Nair G P (2000) Flammability in textiles and routes to flame retardant textiles 1. Colourage 47(8): 27-34.

39. Muniswamy DV, Badami SPK, Lokahtha KL (1980) Effect of UreaPhosphte resin finish on quality characteristics of Cotton fabric. Textile Dyer and Printer 13(9): 37-41.

40. Issacs P, Lewin M, Sello SB, Stevens CV (1974) Flame-Resistant Cellulose Esters. Text Res J 44(9): 700-707.

41. O Brien SJ (1968) Cyanamide-Based Durable Flame-Retardant Finish for Cotton. Text Res J 38(3): 256.

42. Ramachandran T, Vellingiri K, Kanan MSS (2005) A comparative study of durable flame-retardant finish on cotton fabrics. J of Institution of Engineers (India) 85: 29-32.

43. Hoffmann A (1921) The action of Hydrogen Phosphide on Formaldehyde. J Amer Chem Soc 43(7): 1684-1688.

44. Reeves WA, Guthrie J D (1953) Aminization of Cotton. Text Res J 23(8): 522-527.

45. Reeves WA, Flynn F F, Gutherie J D (1955) Laboratory Preparation of Tetrakis-(hydroxymethyl)-phosphonium Chloride. J Amer Chem Soc 77(14): 3923-3924.

46. Beninate J V, Bolyston E K, Drake G L, Reeves W A (1967) Better flameresistant finish for cottons. Text Ind 131(11): 110-112.

47. Beninate J V, Bolyston E K, Drake G L, Reeves W A (1968) Conventional Pad-Dry-Cure Process for Durable- Flame and Wrinkle Resistance with Tetrakis (Hydroxymethyl) Phosphonium Hydroxide (THPOH). Text Res J 38(3): 267-272.

48. Donaldson D J, Diagle J (1969) Phosphorus-Nitrogen Flame Retardant via Copper Complex. Text Res J 39(4): 363-367.

49. Harold C (1961) Flame proofing agents derived from methylol phosphorus polymers. US Pat. 2983623.

50. Anon (1969) Mineral Flame Retardants. CGY Rev 4: 49.

51. Drake GL, Perkins RM, Reeves WA, Flame resistant Cotton-a status Report. J of Fire and Flamability 1(197): 78-87.

52. Xiangdong Z., Chen K, Yi H (2014) Synthesis and application of a formaldehyde-free flame retardant for bamboo viscose fabric. Text Res J 84(14): 1515-1527.

53. Varma IK, Anantha Krishnan SR, Krishnamoorthy S (1988) Effect of chemical treatment on thermal behaviour of jute fibers. Textile Res J 58(9): 486-494.

54. Basak RK, Saha SG, Sarkar AK, Saha M, Das NN, et al. (1993) Thermal properties of jute constituents and flame-retardant jute fabrics. Text Res J 63(11): 658-666.

55. Samanta AK, Bagchi A, Biswas SK (2011) Fire Retardant Finishing of Jute Fabric and its Thermal Behavior using Phosphorous and Nitrogen based Compound. J Polym Mater 28(2): 149-169.

56. Horrocks AR (1986) Flame-retardant finishing of textiles. Rev Prog Coloration 16(1): 62-101.

57. Horrocks AR (1996) Developments in Flame Retardants for Heat and Fire-Resistant Textiles-the Role of Char Formation and Intumescence. Polymer Degradation and Stability 54(2-3): 143-154.

58. Samanta AK, Bhattacharyya (Roy) Reetuparna, Chowdhury Ranjana (2014) Eco-friendly Fire-Retardant Finishing of Jute Fabric by Impregnation or Coating Phosphorylated PVA and its Effect on Physical Properties and Thermal Behaviour of Treated Jute Fabric. International Journal of Applied Engineering Research 9(4): 439-450.

59. Samanta Ashis Kumar, Bhattacharyya (Roy) Reetuparna, Chowdhury Ranjana (2015) Fire-retardant Chemical Finishing of Jute Fabric Using Sulfamate and Urea Mixture. Journal of Materials ASSCIT 1(4): 98-110.

60. Samanta Ashis Kumar, Bhattacharyya (Roy) Reetuparna, Bagchi A Chowdhury Ranjana (2020) Statistical Optimisation of Ammonium Sulfamate and Urea Based Fire Protective Finishing of Jute Fabric by User Defined Quadratic Model (UDQM). In: Majumdar A, Gupta D, Gupta S (eds.), FTC-2020 International Seminar (at IIT-Delhi) Proceedings being published as book chapter in Functional Textiles and Clothing. Springer-Nature, Singapore.

61. Samanta AK, Bhattacharyya R, Jose S, Basu G, Chowdhury R (2017) Fire retardant finish of jute fabric with nano zinc oxide. Cellulose Journal 24(2): 1143-1157.

62. Samanta AK, Bhattacharyay R, Bagchi A, Chowdhuri R (2019) Statistical Optimisation of Nano-Zinc Oxide-Based Fire-Protective Finish on Jute Fabric. In: Majumdar A, Gupta D, Gupta S (eds.), Functional Textiles and Clothing, Springer-Nature, Singapore pp. 167-192.

63. Horrocks AR (2008) Flame-retardant Finishing of Textiles. Coloration Technology 16(1): 62-101.

64. Khalifah AS, Sabyasachi G, Giulio M (2016) Recent Advances for Flame Retardancy of Textiles Based on Phosphorus Chemistry. Polymers 8(9): 319-355.

65. Samanta KK, Basak S, Chattopadhyay SK (2015) Sustainable FlameRetardant Finishing of Textiles Advancement in Technology. In: Subramanian Senthilkannan Muthu (ed.), Handbook of Sustainable Apparel Production, Routledge Handbooks Online p. 51-73.

66. Basak S, Samanta KK, Saxena S, Chattopadhyay SK, Narkar R, et al. (2015) Flame resistant cellulosic substrate using banana pseudostem sap. Pol J Chem Tech 17(1): 123-133.

67. Eaton PM (2008) Flame-retardancy test methods for textiles. Rev Prog Coloration 30(1): 51-62.

68. Ozcan G, Dayioglu H, Condan C (2003) Effect of Gray Fabric Properties on Flame Resistance of Knitted Fabric. Text Res J 73(10): 883-891.

69. Mehta RD (1975) Flammability of metal-cation-exchanged carboxyethylated cottons. Text Res J 44(10): 825-826.

70. Benisek L, Phillips WA (1981) Protective Clothing Fabrics: Part II Against Convective Heat (Open-Flame) Hazards1. Text Res J 51(3): 191-196. 
71. Dawn FS, Morton GP (1979) Cotton Protective Apparel for the Space Shuttle. Text Res J 49: 197-201.

72. Stephenson JE (1984) Flame-Retardant Treatments for Nonwovens and Other Textiles. Amer Dyestuff Repoter 73(10): 26-28.

73. Mehta PC, Sharma VN (1979) How safe are fire retardant finish. Colourage 26(11): 32-35.

74. Nuessle AC, Ford FM, Hall WP, Lippert AL (1956) Some Aspects of the Cellulose-Phosphate-Urea Reaction. Text Res J 26(1): 32-39.

75. Kaushik DP, Chattopadhyay DP, Sharma JK (1994) Durable Flame Retardancy to the Polyester/Viscose Blended Fabrics-II. Manmade Textile in India 37(7): 309.

76. Blanchand EJ, Graves EE (2002) Polycarboxylic acids for flame resistant cotton/polyester carpeting. Text Res J 72(1): 39-43.

77. Dombrowski R (2006) Beyond perception: brominated flame retardants. AATCC Review 6(10): 33-35.

78. Frick JG Jr, Weaver JW, Reid JD (1955) Flame-Resistant Cotton Fabrics An Emulsion Treatment Using an Organic Phosphorus- Bromine Polymer. Text Res J 25(1): 100-105.

79. Peixiu T, Lu Y, Wang D, Zhang G, Zhang F (2019) Synthesis of a new N-P durable flame retardant for cotton fabrics. Polym Degrad \& Stab 165 220-228.

80. Bajaj P, Chakrapani S, Jha NK (1984) Flame Retardant, Durable Press Finishes for Cotton and Polyester/Cellulosic Blends. Text Res J 54(9): 619-630.

81. Nakanishi S, Hashimoto T (1998) Flame Retardation of Cellulosic Fibers as Characterized by Thermal Degradation Behavior. Text Res J 68(11): 807-813.

82. Blanchand EJ, Graves EE (2003) Phosphorylation of Cellulose with Some Phosphonic Acid Derivatives. Text Res J 73(1): 22-26.

83. Mamalis P, Andreopoulos A, Spyrellis N (2001) The effect of a durable flame-retardant finishing on the mechanical properties of cotton knitted fabrics. Int J of Clothing Sci Tech 13(2): 132-144.
84. House James R, James D Squire (2004) Effectiveness of Proban® flame retardant in used clothing. Int J of Clothing Sci Tech 16(4): 361-367.

85. Giraud S, Bourbigot S, Rochery M, Vroman I, Tighzert L, et al. (2001) Flame Behavior of Cotton Coated with Polyurethane Containing Microencapsulated Flame Retardant Agent. Industrial Text J 31(1): 1126.

86. Lee SE (2002) Possible phosphorus-bromine synergy in polyestercotton fabrics treated with tetrabromobisphenol-A and diammonium phosphate. J App Polym Sci 84(1): 172.

87. Garba B, Eboatu AN, Abdulrahman FW (1996) Effect of Dimethylol Urea as a Flame Retardant Formulation on Some Cellulosic Fabric Materials. Fire and Materials 20(3): 155-157.

88. Reddy PRS, Agathian G, Kumar A (2005) Ionizing radiation graft polymerized and modified flame-retardant cotton fabric. Radiation Phys and Chem 72(4): 511-516.

89. Horrocks AR, Price D, Akalm M (1996) FTIR analysis of gases evolved from cotton and flame retarded cotton fabrics pyrolysed in air. Polymer Degradation and Stability 52(2): 205-213.

90. Kandola BK, Horrocks AR, Price D, Coleman GV (1996) Flame-Retardant Treatments of Cellulose and Their Influence on the Mechanism of Cellulose Pyrolysis. J Macromol Sci 36(4): 721-794.

91. Kaur I, Rajneesh Ms, Vibha (2007) Flame retardant cottonfabric through graft co-polymerisation. Defence Sci J 57(2): 249-258.

92. Nakanishi S, Masuko F, Hori K, Hashimoto T (2000) Pyrolytic gas generation of cotton cellulose with and without flame retardants at different stages of thermal degradation: Effects of nitrogen, phosphorus, and halogens. Textile Research J 70(7): 574-583.

93. Nakanishi S, Masuko F, Hashimoto T (1999) Durable flam-retardant finished cotton fabrics characterized by thermal degradation behaviors. J Applied Polymer Sci 71(6): 957-987.

94. Rearick WA, Wallace ML, Martin VB, Cary NC, Wakelyn PJ (2002) Flammanlity consideration for raised surface apparel. AA TCC Review 12.

\section{Your next submission with Juniper Publishers will reach you the below assets}

- Quality Editorial service

- Swift Peer Review

- Reprints availability

- E-prints Service

- Manuscript Podcast for convenient understanding

- Global attainment for your research

- Manuscript accessibility in different formats

( Pdf, E-pub, Full Text, Audio)

- Unceasing customer service

Track the below URL for one-step submission https://juniperpublishers.com/online-submission.php 